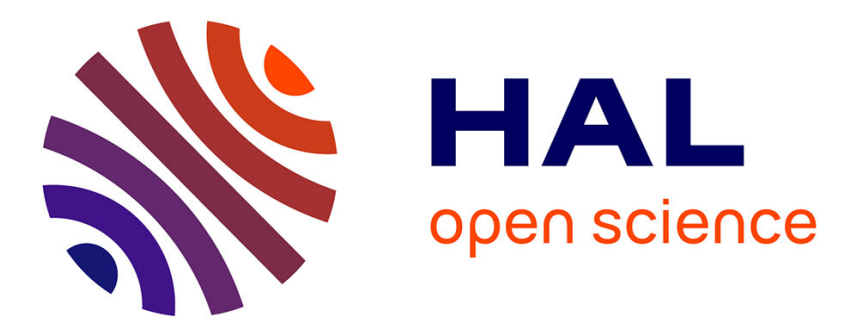

\title{
Structure of graphite precipitates in cast iron
}

Koenraad Theuwissen, Jacques Lacaze, Lydia Laffont-Dantras

\section{To cite this version:}

Koenraad Theuwissen, Jacques Lacaze, Lydia Laffont-Dantras. Structure of graphite precipitates in cast iron. Carbon, 2016, vol. 96, pp. 1120-1128. 10.1016/j.carbon.2015.10.066 . hal-01564122

\section{HAL Id: hal-01564122 \\ https://hal.science/hal-01564122}

Submitted on 18 Jul 2017

HAL is a multi-disciplinary open access archive for the deposit and dissemination of scientific research documents, whether they are published or not. The documents may come from teaching and research institutions in France or abroad, or from public or private research centers.
L'archive ouverte pluridisciplinaire HAL, est destinée au dépôt et à la diffusion de documents scientifiques de niveau recherche, publiés ou non, émanant des établissements d'enseignement et de recherche français ou étrangers, des laboratoires publics ou privés. 


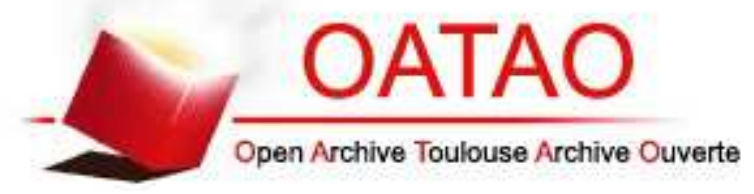

\section{Open Archive TOULOUSE Archive Ouverte (OATAO)}

OATAO is an open access repository that collects the work of Toulouse researchers and makes it freely available over the web where possible.

This is an author-deposited version published in : http://oatao.univ-toulouse.fr/ Eprints ID : 16713

To link to this article : DOI: $10.1016 /$ j.carbon.2015.10.066 URL : http://dx.doi.org/10.1016/j.carbon.2015.10.066

To cite this version : Theuwissen, Koenraad and Lacaze, Jacques and Laffont-Dantras, Lydia Structure of graphite precipitates in cast iron. (2016) Carbon, vol. 96. pp. 1120-1128. ISSN 0008-6223

Any correspondence concerning this service should be sent to the repository administrator: staff-oatao@ listes-diff.inp-toulouse.fr 


\title{
Structure of graphite precipitates in cast iron
}

\author{
K. Theuwissen, J. Lacaze, L. Laffont ${ }^{*}$ \\ Institut Carnot CIRIMAT, ENSIACET, 4, Allée Emile Monso, BP 44362, 31030 Toulouse, Cedex 4, France
}

\begin{abstract}
A B S T R A C T
This study presents microstructural investigations of graphite precipitates found in cast irons. Binary $\mathrm{Fe}$ $-\mathrm{C}, \mathrm{Fe}-\mathrm{C}-\mathrm{Sb}$ and $\mathrm{Fe}-\mathrm{C}-\mathrm{Ce}$ alloys containing different graphite morphologies (flake and spheroidal) were produced and compared to commercial irons in an attempt to rationalize the effect of $\mathrm{Sb}$ and $\mathrm{Ce}$ on graphite growth. The extensive use of transmission electron microscopy (mainly electron diffraction and high resolution lattice fringe imaging) enabled further understanding of graphite growth mechanisms. It was found that the inner structure of graphite precipitates consists of growth blocks stacked upon each other, for all investigated morphologies. This suggests that graphite crystals develop mainly by a 2D nucleation and growth mechanism, and that the final shape of the precipitates is associated to the occurrence of crystallographic defects in the graphite lattice (such as twins, misorientations and rotations) during growth.
\end{abstract}

\section{Introduction}

Cast irons are the most important casting materials and their use is justified by the wide range of mechanical properties which can be achieved, associated with their competitive price. These materials have been used for thousands of years, dating back to 500 BC. in ancient China [1]. Cast irons containing iron carbide (cementite) are named "white" whereas those in which carbon is present as graphite are called "grey" irons. In these latter, those having graphite precipitates with a flake-like morphology show a good damping capacity and compressive strength but also low tensile strength and ductility [2]. In the 1940's a graphite spheroidization treatment was discovered [3] where addition of controlled amounts of magnesium, cerium or calcium to the iron melt prior to casting leads to the formation graphite precipitates with a nearly-spherical shape. This new material called "spheroidal graphite cast iron" or "ductile iron" has improved mechanical properties such as ductility and fracture toughness as compared to those of flake-graphite iron and has been used in piping systems, automotive parts and many other applications.

Further research showed that the shape of graphite precipitates in cast irons is very sensitive to small variations in melt composition. This can be beneficial: compacted graphite cast irons, which have a good damping capacity and a good thermal conductivity, can

\footnotetext{
* Corresponding author

E-mail address: lydia.laffont@ensiacet.fr (L. Laffont).
}

be obtained by reducing the magnesium content of the melt with respect to the amount used in ductile iron production $[1,4,5]$. However, this can also be detrimental, as degenerate graphite morphologies can appear in ductile iron castings if certain deleterious elements are present in the melt due to poor charge material quality (purity) or due to the inoculation treatment. The formation of such peculiar microstructures and its important consequences on the mechanical properties of cast irons encouraged intensive research to understand graphite growth mechanisms in cast iron melts. The presence of defects in the graphite lattice, the role of foreign elements and cooling rate are some key points which have been considered to discuss possible graphite growth mechanisms.

There is no doubt that the elongated shape of lamellar graphite results from a preferential growth along the prismatic $a$ axes of graphite. On the contrary, spheroidal growth is associated with an apparent growth along the $c$ axis which is found to be radially orientated in spheroids. Several models have been proposed to describe such a modification of the relative growth rates along $a$ and $c$ axes of graphite. It has been shown that multiple twinning could produce spherulitic crystals in polymer melts [6] and a regular branching model following a similar mechanism was proposed to describe spheroidal growth of graphite [7]. Some authors have considered that the enhanced $c$ axis growth of graphite was made possible by means of screw dislocations generated by spheroidizing elements adsorbed at growth ledges which would enable spiral growth and eventually lead to the formation of spheres [8]. It has been further stated that spiral growth does not require adsorption 
of foreign elements in graphite, but would indeed form spherical aggregates consisting of multiple conical helices $[9,10]$. This model had the advantage of reproducing spheroidal structures which are close to those observed experimentally but it has been subjected to further discussion by its own authors [11].

The above models have been criticized since long because there are evidences that graphite growth proceeds mainly along the $a$ axis also in spheroids, even though the overall shape (radial direction of the spheroids) develops along the $c$ direction [12]. For example, some authors have tried to explain the apparent growth along the $c$ axis by a circumferential extension of graphite and/or wrapping of carbon layers [13]. In this line, it has been previously shown that crystalline defects observed along spheroids' radius could hardly be reconciled with a continuous growth along the $c$ direction [14].

It is clear that despite considerable amount of research, the mechanisms of spheroidal graphite growth in metallic melts are still unclear. In particular, if graphite growth in spheroids proceeds along the $a$ direction as does flake graphite, the similarities and possible differences leading to such different overall shapes are worth of further studies. In this article, the microstructural features of different graphite morphologies (spheroidal and flake) appearing in commercial cast irons and synthetic alloys are investigated with microscopy techniques. The results are used to follow through on recent advances in the understanding of this matter [15] and question some of the models that have been previously proposed.

\section{Materials and experimental methods}

Microstructural investigations were first carried out on a commercial spheroidal graphite cast iron kindly provided by Azterlan Metallurgy research center. The composition of this material is reported in Table 1 and details about alloy preparation can be found elsewhere [16].

In order to produce flake graphite cast irons, samples of the same spheroidal graphite cast iron were remelted as described previously [17]. The samples, placed in graphite crucibles, were heated to $1350{ }^{\circ} \mathrm{C}$ in a resistance furnace and held at that temperature for $10 \mathrm{~min}$. This stage enabled volatilization of the magnesium added for spheroidization and carbon enrichment of the alloys. From the graphite liquidus in the $\mathrm{Fe}-\mathrm{C}$ phase diagram, the carbon enrichment may be estimated to $0.4 \mathrm{wt} . \%$. They were then cooled in about $10 \mathrm{~min}-1180{ }^{\circ} \mathrm{C}$, i.e. above the $\mathrm{Fe}-\mathrm{C}$ eutectic, and maintained at that temperature for $30 \mathrm{~min}$ so as to promote nucleation and growth of graphite crystals in a Fe-rich melt. Following this stage, the samples were rapidly extracted from the furnace and quenched with an air blowing device which led to rapid solidification of the remaining melt at a rate of about $250{ }^{\circ} \mathrm{C} /$ min.

Synthetic $\mathrm{Fe}-\mathrm{C}$ alloys were prepared by placing a piece of pure Fe in a graphite crucible (for chemical analysis) and then following the same thermal cycle as above under either air or primary dynamic vacuum (about $5 \cdot 10^{-6} \mathrm{MPa}$ ). Similarly, synthetic $\mathrm{Fe}-\mathrm{C}-\mathrm{Ce}$ alloys were prepared by locating some $\mathrm{Ce}$ at the bottom of a graphite crucible and pure Fe on top of it, the amount of Ce being $2 \%$ of that of $\mathrm{Fe}$. $\mathrm{Fe}-\mathrm{C}-\mathrm{Sb}$ alloys were obtained from a $\mathrm{Fe}-0.5 \% \mathrm{Sb}$ alloy prepared by induction melting and then following the same procedure than for $\mathrm{Fe}-\mathrm{C}$ samples. According to the $\mathrm{Fe}-\mathrm{C}$ phase

Table 1

Composition of the spheroidal graphite cast iron (in wt. \%).

\begin{tabular}{lllllllll}
\hline Alloy & $\mathrm{C}$ & $\mathrm{Si}$ & $\mathrm{Mn}$ & $\mathrm{P}$ & $\mathrm{S}$ & $\mathrm{Mg}$ & $\mathrm{Cu}$ & $\mathrm{Fe}$ \\
\hline $10 \mathrm{~F} 2$ & 3.64 & 2.05 & 0.11 & 0.033 & 0.015 & 0.037 & 0.04 & balance \\
\hline
\end{tabular}

diagram, the carbon content of these synthetic alloys should be of the order of $4.6-4.7 \mathrm{wt} . \%$ but no chemical analysis was performed because the samples were too small for both metallographic inspection and chemical analysis. One of the $\mathrm{Fe}-\mathrm{C}-\mathrm{Ce}$ samples investigated in the present work was quenched when the temperature reached $1180^{\circ} \mathrm{C}$, i.e. it did not undergo any holding at that temperature.

The samples were cross-sectioned and polished for metallographic examination using a Nikon MA200 inverted metallographic microscope. Specimens for transmission electron microscopy (TEM) were prepared by grinding and polishing these sections to an appropriate thickness. $3 \mathrm{~mm}$ discs were then punched (extracted) from the samples, dimpled to about $20 \mu \mathrm{m}$ and further thinned by ion milling using a Gatan Precision Ion Polishing System (PIPS).

One TEM sample was prepared from the industrial spheroidal graphite cast iron using a JEOL focused ion beam (FIB) following the procedure detailed in Ref. [18] in order to facilitate homogeneous and localized thinning of a relatively large specimen. All specimens were examined in a JEOL 2100F FEG-TEM operated at $200 \mathrm{kV}$. Crystal orientation maps obtained on the FIB sample were produced in a JEOL 3010 TEM operated at $300 \mathrm{kV}$ equipped with a Digistar system for automated crystal orientation mapping (ACOM).

Finally, a LEO 435VP scanning electron microscope (SEM) was used to image samples after deep-etching with a $37 \% \mathrm{HCl}$-ethanol solution.

\section{Results and discussion}

\subsection{Characterization of graphite in commercial alloys}

\subsubsection{Spheroidal graphite}

Metallographic analysis of the commercial spheroidal graphite cast iron showed that its microstructure consists of spheroidal graphite precipitates of good nodularity (Fig. 1a). An average diameter of $19 \mu \mathrm{m}$ and a density of $400 \mathrm{~mm}^{-2}$ were determined by image analysis of 4 fields of view of about $0.8 \mathrm{~mm}^{2}$ on the base material. These precipitates have an irregular outer surface as shown in the micrograph of Fig. 1b obtained after deep etching of the samples. Such a feature has been described as cabbage leaf-like [12] and relates to lateral extension of the outermost graphite layers along the surface of the spheroids, presumably during solidstate cooling of the material.

Previous transmission electron microscopy carried out on spheroidal graphite cast irons revealed that sections of the spheroidal precipitates are made of conical sectors and selected area electron diffraction (SAED) patterns taken in these sectors revealed that $c$ axes of graphite are oriented radially, i.e. roughly parallel to the spheroids' radius in each sector [9,14,19-21]. Misorientations between the (0002) reflections in the diffraction patterns of different locations within one single sector suggest that these fanlike areas are made of domains of similar orientations which have been referred to as crystallites in investigations of carbonaceous materials [22]. These domains are formed during graphite precipitation upon solidification of the iron. As such, these domains of similar orientation can be considered as growth blocks, which, stacked upon each other, form the inner structure of graphite spheroids. These growth blocks have a thickness between 10 and $100 \mathrm{~nm}[14,19-21]$ and a length of a few micrometers [21].

The bright field image (Fig. 2) of one part of a spheroidal graphite precipitate shows an inner structure composed of sectors and a thin outer layer with a less defined structure. Graphite at the periphery of such spheroids appeared to be much less organized than in the bulk of the sectors as shown by spotty rings in the diffraction pattern of Fig. 2a. For comparison, a selected area diffraction pattern was taken in the bulk of a sector with the same 

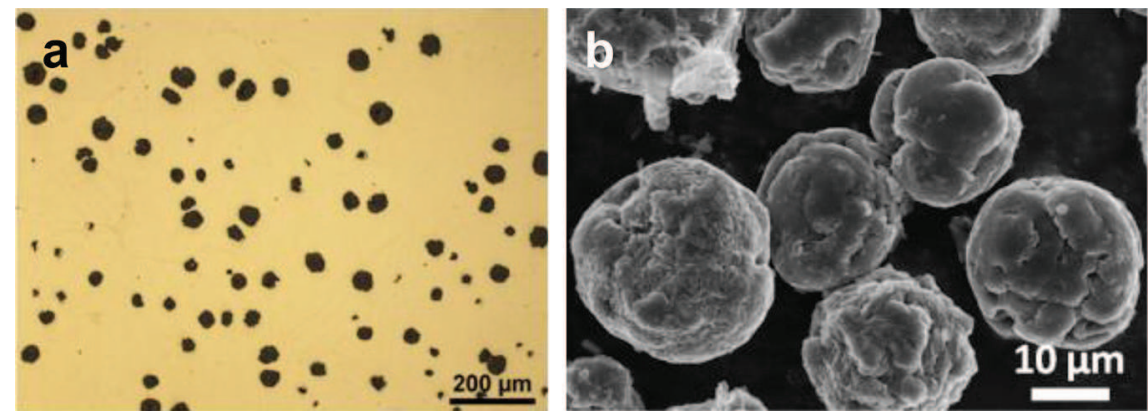

Fig. 1. a) Optical micrograph of a spheroidal graphite cast iron section and b) SEM image of extracted spheroids. (A color version of this figure can be viewed online.)

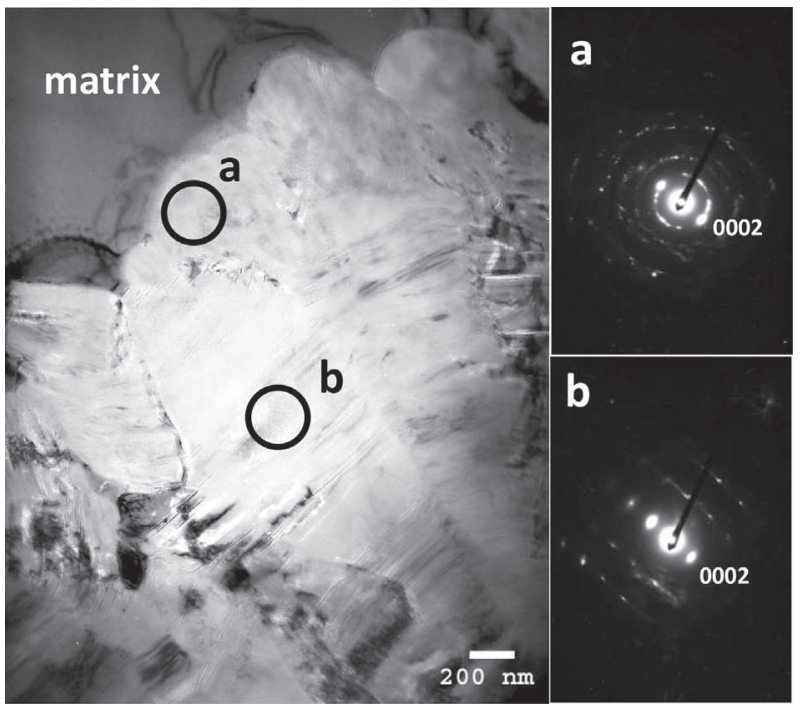

Fig. 2. Bright field TEM image of a sector in a graphite spheroid combined with SAED patterns a) at the periphery and b) in the bulk of the sector (the selected areas used to perform diffraction are schematized by the two black circles in the bright field image).

aperture size showing one clear orientation (Fig. 2b). It can be concluded from these results that, at the periphery of the spheroids, domains of similar orientation have a smaller size than in the bulk of sectors. Growth blocks are thus smaller in these locations and or present higher relative misorientations between each other. Comparable features have been produced by heat treatments of cast irons and steels [21,23-25]. The authors related the formation of this "microcrystalline graphite" to solid-state carbon deposition during decomposition of the matrix.

A general overview of the inner structure of such spheroidal graphite precipitates was investigated in a previous study by means of Automated Crystal Orientation Mapping in a TEM [18]. The results, summarized with orientation maps such as those in Fig. 3, clearly show boundaries between neighbouring sectors as well as misorientations within them. Most of the misorientation angles were observed to have values of $10-15^{\circ}, 20-22^{\circ}$ and $27-30^{\circ}$ which correspond to known twin angles, though some other values could also be measured. Sharp colour changes within sectors such as the blue to green alternating in the lower right part of Fig. 3 represent rotations of $27^{\circ}$ of the $c$ axis of graphite [18]. This value corresponds to a low energy stacking fault in the graphite lattice as predicted by the coincidence site lattice theory [26,27] and determined in recent studies by means of atomistic calculations $[28,29]$. According to some authors $[9,26]$, this rotation is likely to occur in a growing graphite crystal and would consequently provide steps for atom attachment [30].

After describing the crystal orientation of graphite inside sectors, which consisted mainly in small angle misorientations as well as rotations around the $c$ axis [18], TEM was used to study the interface between sectors. Diffraction patterns taken over two adjacent sectors (Fig. 4a and b) show a sharp interface clearly defined by a difference in contrast and two distinctive $c$ axis orientations. A high resolution TEM (HRTEM) lattice fringe image taken at the interface between neighbouring sectors in Fig. 4c shows relatively straight fringes on left and right hand sides which are characteristic of a highly graphitic material. Nevertheless, $c$ axes from both parts of the image do not have the same orientation and they are separated by an interface within which the graphene layers are rippled in a transition zone with a width varying from 4 to $9 \mathrm{~nm}$. Indeed, recent studies have shown that grain boundaries in graphene are produced by the introduction of defects which result in an out-of-plane inflexion of the layers [29]. Interestingly, calculations [28] have shown that the grain boundaries with the lowest formation energy are the most likely to be formed, and these cause inflexion angles of $13.2^{\circ}, 21.8^{\circ}$ and $27.8^{\circ}$ close to the ones measured
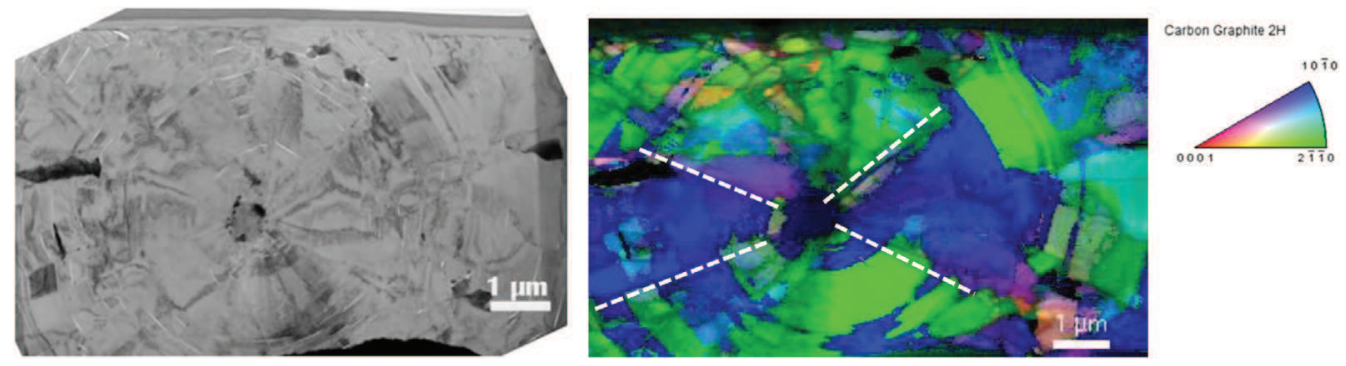

Fig. 3. Photomontage of TEM images of a diametrical section of graphite spheroid combined with the crystal orientation map of graphite obtained by ACOM; apparent boundaries between sectors are highlighted by white dotted lines (dark areas at the periphery of the nodule are iron-rich particles that were not indexed). (A color version of this figure can be viewed online.) 

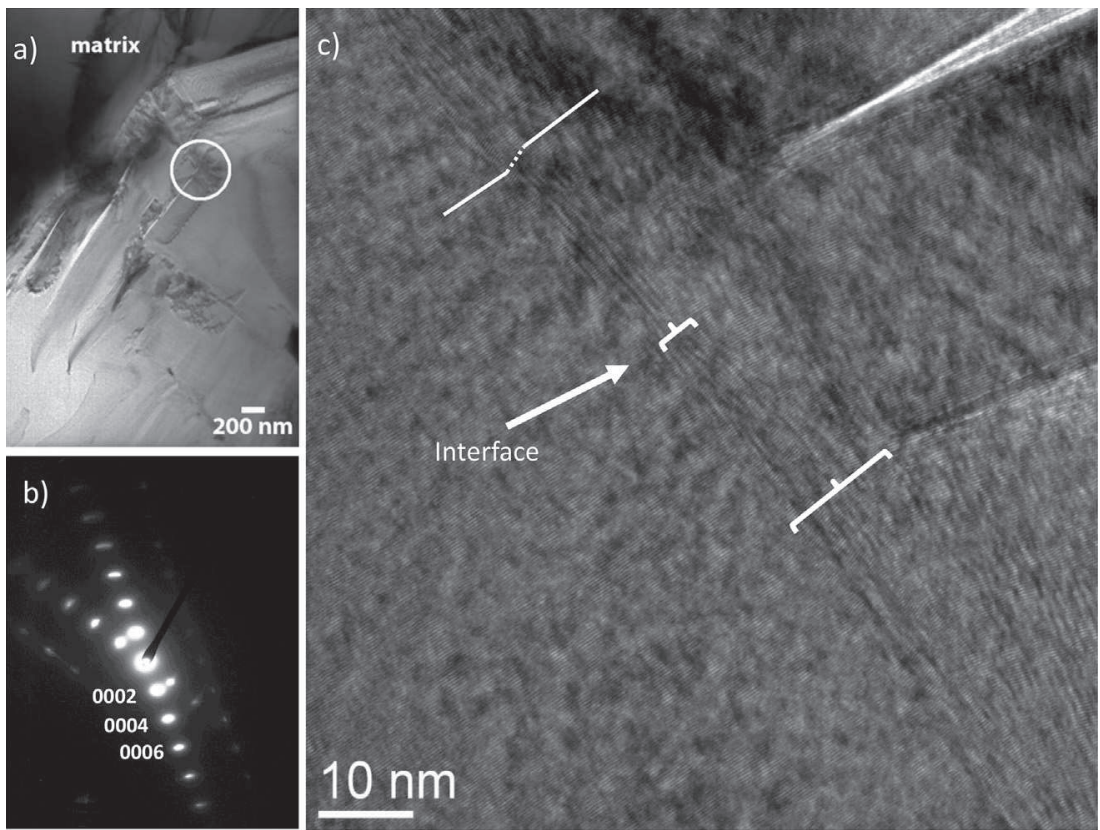

Fig. 4. a) Bright field TEM image of a boundary between two neighbouring sectors, b) SAED diffraction corresponding to the white circle in the bright field image and c) lattice fringe image of the same interface between neighbouring sectors.

experimentally in this study [14].

It thus appears that crystallographic defects such as twins are often present in graphite [31-34], and result in the formation of grain boundaries $[28,29]$ which accommodate the misorientations between neighbouring sectors.

The observations can be summarized as follows: graphite growth blocks nucleate and grow during solidification of cast iron and are stacked to form conical sectors or fan-like areas. Defects in the graphite structure (misorientations and rotations) are found at the interface between neighbouring sectors creating apparent grain boundaries and also within conical sectors. The spheroidal precipitates formed by multiple sectors can be surrounded by areas presenting small-sized orientation domains which are presumably formed in the solid-state, after solidification.

\subsubsection{Flake graphite}

Samples of flake graphite irons produced by remelting the initial spheroidal graphite alloy present a microstructure illustrated with Fig. 5a. Relatively large-sized graphite precipitates are seen mainly in the upper part of the samples and at its edges. These are primary precipitates which formed upon cooling from $1350{ }^{\circ} \mathrm{C}$ and holding at $1180^{\circ} \mathrm{C}$. During this stage, graphite precipitates nucleated at the crucible walls and eventually detached to grow freely in the liquid as described by Patterson et al. for similar experiments [35]. Due to density difference between graphite and iron, these precipitates float to the top of the samples [36]. The rest of the samples consists of an iron-rich matrix containing undercooled graphite of smaller size and irregular shape formed during quenching. Such a distribution of graphite precipitates in the sample is inherent to the preparation process and was therefore observed in all laboratory remelted samples which will be presented further. In this study, emphasis will be put on primary graphite. It is generally established that graphite flakes are extended along the $a$ direction and that $c$ axis of graphite is perpendicular to the flake's length. The polarized light micrograph of Fig. 5b shows that the orientation of the $c$ axis is nearly identical in the whole illuminated flake.

Fig. 6 is a bright field TEM image taken at low magnification to show the whole width of a graphite flake. Darker areas on either side of the flake correspond to the surrounding Fe-rich matrix. Selected area diffraction patterns taken at 2 different locations in the flake with a $250 \mathrm{~nm}$ aperture show different $c$ axis orientations as seen by the (0002) spots in Fig. 6a and b. [0001] directions in diffraction pattern $\mathrm{b}$ are misoriented by $21^{\circ}$ with respect to that of diffraction pattern a.
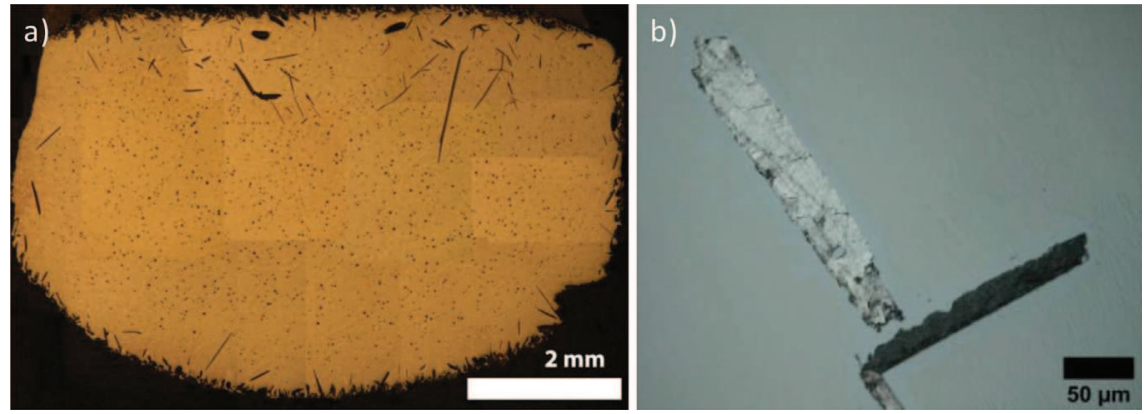

Fig. 5. a) Photomontage of light micrographs showing a sample of flake graphite iron produced by remelting the initial spheroidal graphite alloy and b) polarized light micrograph of graphite flakes. (A color version of this figure can be viewed online.) 

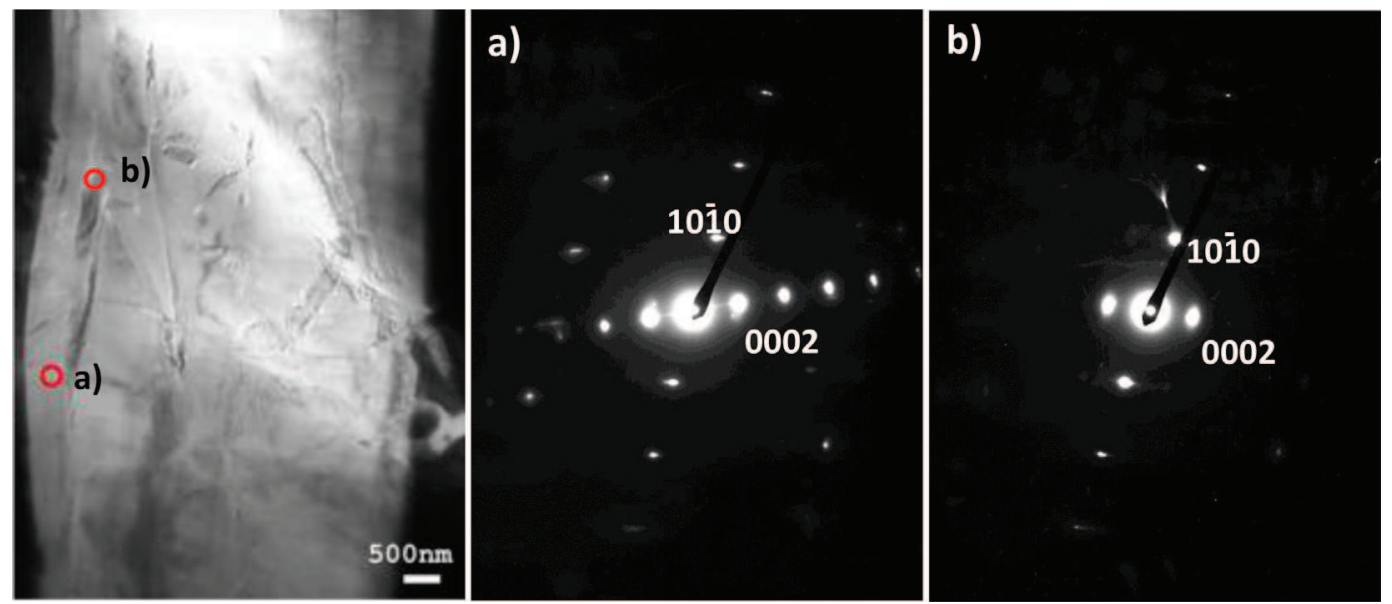

Fig. 6. Bright field image of flake graphite associated and SAED patterns associated to the labelled areas in the bright field image. (A color version of this figure can be viewed online.)

These misorientations do not seem to affect the overall growth direction of the flake which remains relatively straight with a fairly homogeneous thickness. However, the presence of such misorientations indicates that the graphite flakes consist of structural entities, or growth blocks which are stacked upon each other to form flakes of a nearly constant thickness. The length of these growth blocks may be much larger than in the case of spheroidal graphite irons, but their thickness is very similar. Comparable to what was observed for spheroidal graphite is the fact that interfaces between growth blocks of different orientations show bent and rippled graphene stacks as shown in Fig. 7. These results demonstrate common features in the inner structures of flake and spheroidal graphite at the microscopic scale.

\subsection{Graphite growth in synthetic alloys}

Synthetic alloys prepared in both air and vacuum atmospheres led to similar microstructures characterized by relatively few primary graphite precipitates as compared to commercial alloys. This is due to the fact that fewer nucleation sites were available in this

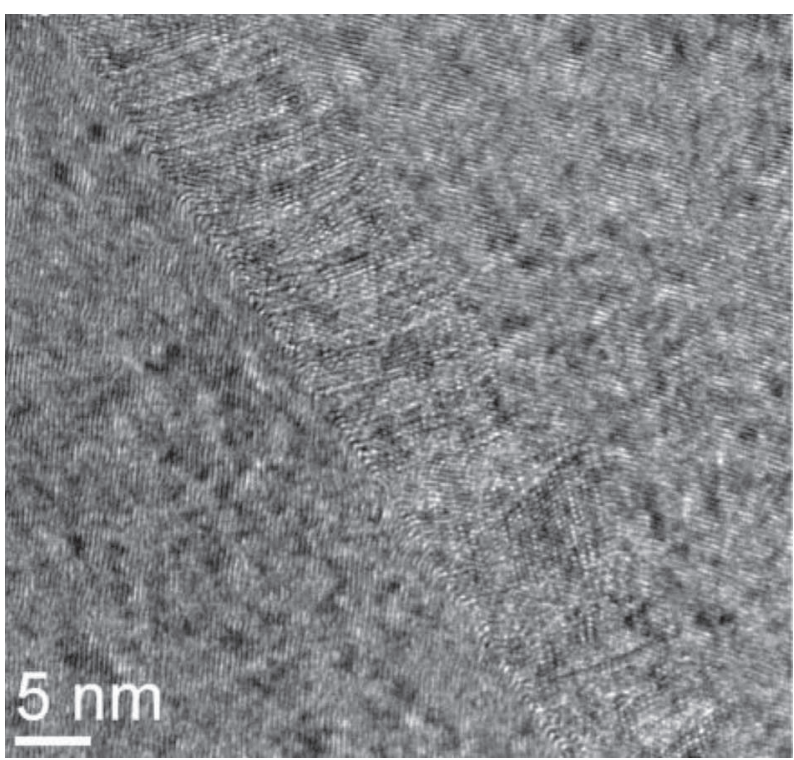

Fig. 7. Lattice fringe image of an area of orientation change inside a flake graphite. case because no inoculant was added and the melt was certainly cleaner.

\subsection{1. $\mathrm{Fe}-\mathrm{C}$ samples}

The optical micrograph in Fig. 8a shows typical flakes observed in a $\mathrm{Fe}-\mathrm{C}$ sample. There are apparent thickness variations along the flakes, indicated by the arrows in the micrograph. This reveals a multi-stage growth in which the steps seen in the optical micrograph of Fig. 8a correspond to growth blocks which extend laterally over the underlying flake as shown in the scanning electron micrograph of a deep etched sample (Fig. 8b). This suggests that lateral extension of consecutive growth blocks results in thickening of the flakes as described by Amini and Abbaschian [15]. It is interesting to note that no differences were observed between samples processed in air and vacuum.

These observations agree with the views of Minkoff [37] who showed that substrate steps, edges or grain boundaries provide nucleation sites for new graphite layers. The thickening rate depends on the nucleation rate of new blocks which then extend along the surface of the flake. Such blocks were reported by Franklin and Stark $[38,39]$ who noted a periodic increase of the sulfur signal when carrying out depth profiles of graphite flakes using secondary ion mass spectrometry. The authors attributed this observation to the presence of sulfur atoms on the basal surfaces of graphite, where this element is known to preferentially adsorb. This was considered by the authors as evidence that graphite flakes consist in a buildup of individual lathes.

\subsection{2. $\mathrm{Fe}-\mathrm{C}-\mathrm{Sb}$ samples}

$\mathrm{Fe}-\mathrm{C}-\mathrm{Sb}$ samples also underwent experiments of carbon enrichment in air and vacuum. The role of antimony in graphite growth modification is not yet clear but it is often used in industrial practices to prevent chunky graphite formation in alloys containing rare earths [40]. The results obtained in this study do not show any significant change in the microstructure with respect to that of pure binary alloys, i.e. the primary graphite precipitates are mainly of the flake-type. Nevertheless, primary graphite flakes appeared to be curved and bent as shown in Fig. 9.

Transmission electron microscopy was performed to examine such precipitates. Fig. 10 shows a long graphite flake, made of several areas of different orientations, delimited by the black dotted lines. The apparent curvature of the flake is caused by multiple changes of orientations in the flake's growth direction, which could have been promoted by the presence of antimony in the alloy. It 


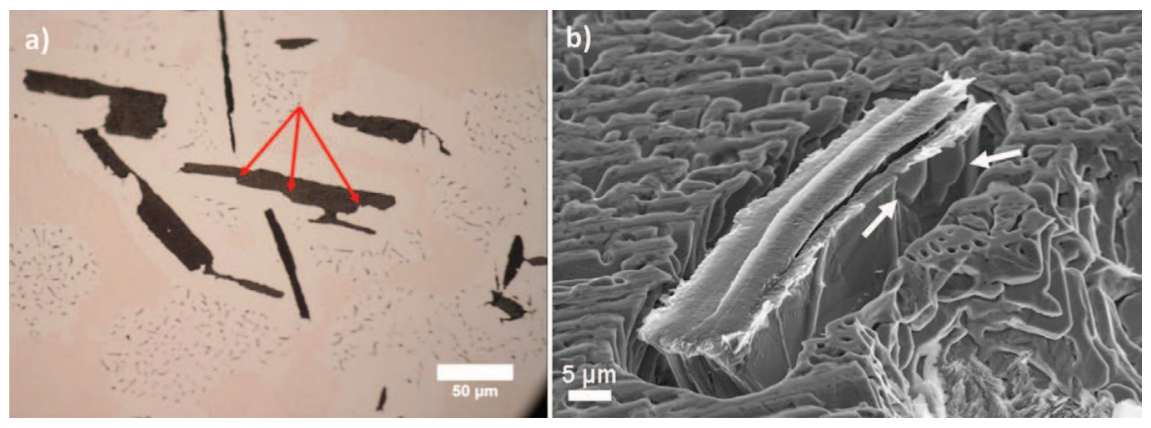

Fig. 8. a) Optical micrograph of typical flakes obtained in Fe-C alloy, b) SEM image of a flake after deep etching. (A color version of this figure can be viewed online.)

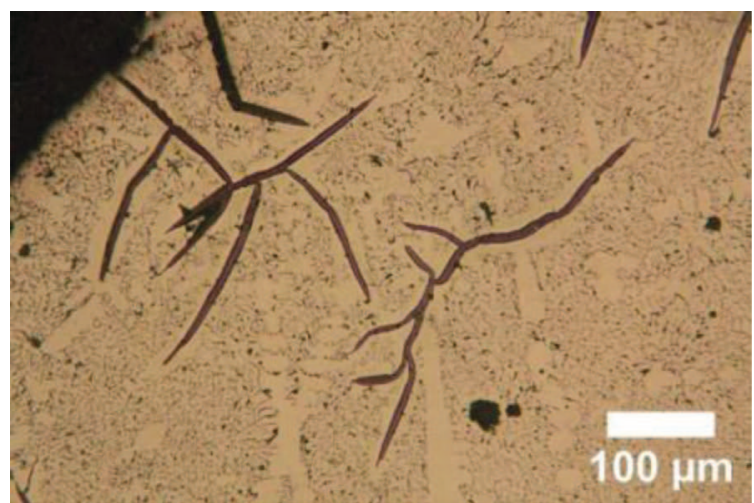

Fig. 9. Optical micrograph of a Fe-C-Sb sample. (A color version of this figure can be viewed online.)

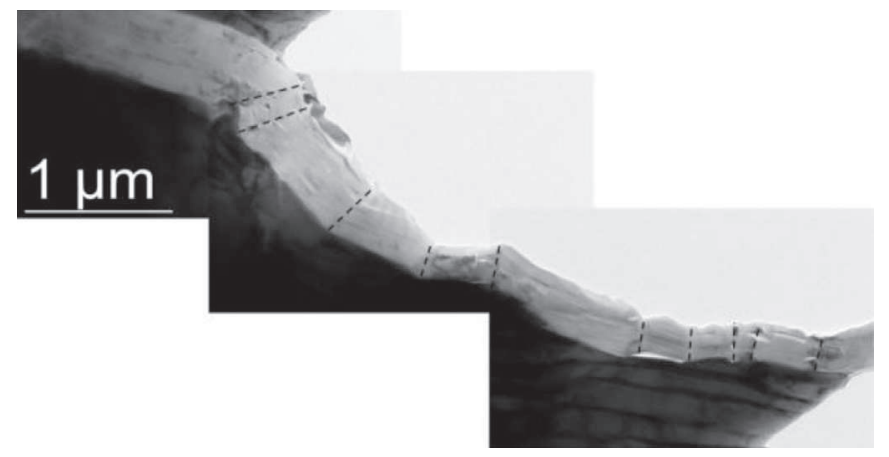

Fig. 10. Bright field TEM image of a graphite flake showing successive segments of different orientations along the length of the flake.

thus seems that antimony promotes growth defects in the graphite lattice. With the necessary precautions, this could be linked with ab-initio calculations which have shown that $\mathrm{Sb}$ reduces graphite twinning energy [41]. As for the case of $\mathrm{Fe}-\mathrm{C}$ alloys, microstructures were similar for samples produced in air and vacuum.

\subsection{3. $\mathrm{Fe}-\mathrm{C}-\mathrm{Ce}$ samples}

Samples were prepared in air and vacuum as for the other synthetic alloys. Compared to usual gray irons, the flakes of the samples prepared in air were rather thick and short and could be called platelets as reported in the literature [42]. These platelets sometimes show evidence of growth steps (white arrows in Fig. 11a) suggesting that in this case also thickening occurs by a 2D nucleation and growth mechanism.

The samples prepared in vacuum showed peculiar microstructures: primary graphite precipitates with relatively rounded shapes were observed, reminiscent of spheroidal graphite precipitates. For the sample quenched directly after holding at $1180^{\circ} \mathrm{C}$, the graphite sections are not complete disks but are made of conical sectors separated by matrix intrusions (Fig. 11b). The extent of these intrusions is variable, but it suggests that several sectors grew independently. It can be referred to as exploded graphite, a term used in the literature to describe a variety of incomplete/degenerate spheroidal graphite precipitates. In some cases, isolated graphite sectors were observed.

The microstructural analysis of the samples reveals that, under similar conditions, removing oxygen (by performing experiments in medium vacuum) enabled the formation of sectors of spheroidal graphite in Ce-bearing alloys. The exploded or spheroidal-like morphology was not achieved without the addition of $\mathrm{Ce}$, even when the $\mathrm{Fe}-\mathrm{C}$ alloys were produced in primary vacuum. This indicates that Ce does first act as an oxygen scavenger as reported in the literature. In this case, it probably gathers the oxygen remaining in the crucible by forming cerium oxides, which is confirmed by the presence of cerium (and oxygen) bearing inclusions found in the samples.

It is worth noting that such exogenous particles can act as nucleants for graphite. The micrograph in Fig. 12, where a graphite particle develops from the outer surface of an inclusion containing $\mathrm{Ce}$ and $\mathrm{O}$, is an example of this. Moreover, such proximity between graphite and Ce could ease the incorporation of $\mathrm{Ce}$ atoms in graphite [43] and possibly lead to the formation of defects in the graphite lattice thus contributing to morphological modifications of the precipitates.

Transmission electron microscopy of a sample that was subjected to the $30 \mathrm{~min}$ holding at $1180^{\circ} \mathrm{C}$ revealed unusual features in the sectors of primary exploded graphite (Fig. 13). Monitoring the $c$ axis orientation over the whole sector showed that in its inner part, [0001] direction is roughly parallel to the radius of the (incomplete) spheroid. The outer part of the sector is a rim with a different contrast in the bright field image, in which the orientation of graphite changes progressively to surround the inner part of the sector. For clarity, approximate $c$ axis orientations are represented schematically in Fig. 13b.

The structural differences of graphite in the two locations suggest that the center and the periphery of the sector grew following different mechanisms occurring at two different growth stages. During cooling from $1350^{\circ} \mathrm{C}$ to $1180^{\circ} \mathrm{C}$, primary graphite nucleates and grows freely in the melt. This growth stage is expected to have led to the formation of the inner part of the sector. During holding at $1180{ }^{\circ} \mathrm{C}$, graphite growth is expected to occur in a steady state during which there could be Ce build-up in the liquid, close to the graphite/matrix interface and some of it could be absorbed by the growing graphite.

Energy dispersive X-ray analysis showed the presence of Ce in the outer rim, whereas this element was not detected in the central 


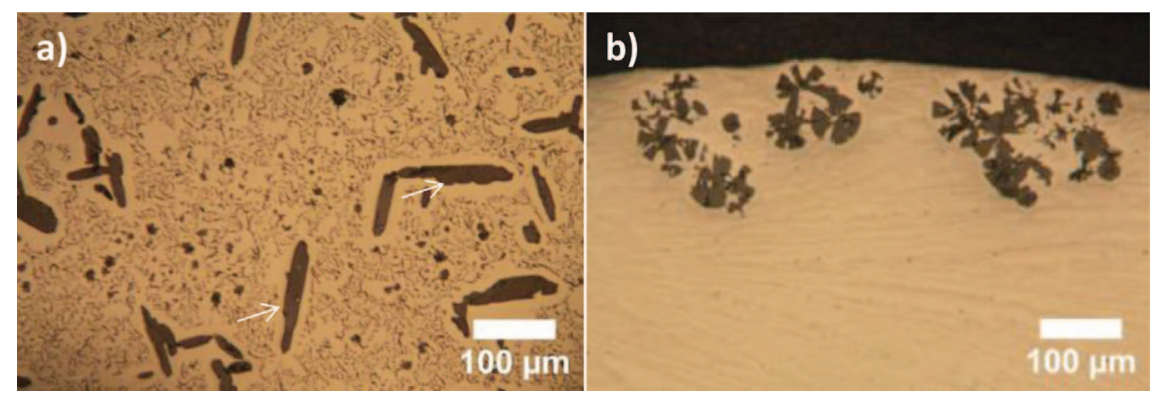

Fig. 11. Optical micrographs of $\mathrm{Fe}-\mathrm{C}-\mathrm{Ce}$ alloys a) in air and b) in vacuum. (A color version of this figure can be viewed online.)

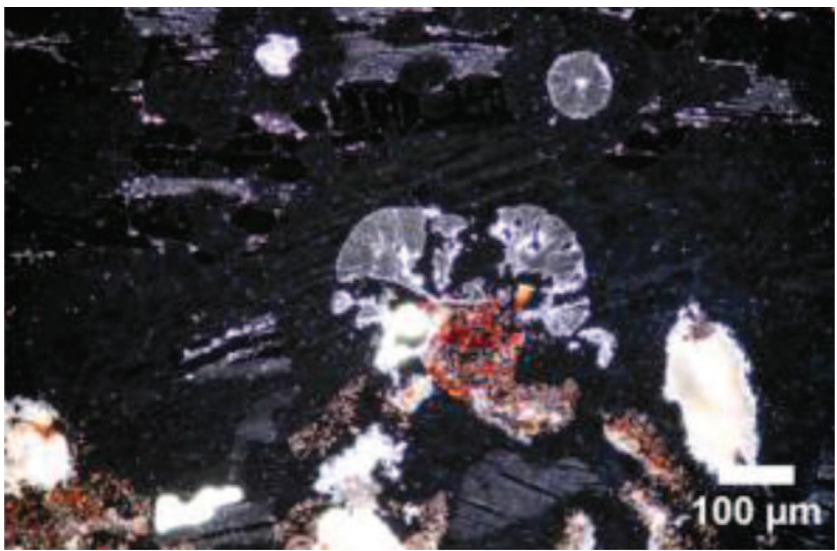

Fig. 12. Optical dark field micrograph of a Fe-C-Ce alloy - Graphite: grey, matrix: black, Ce and O: red and porosity: white. (A color version of this figure can be viewed online.) part of the sector. It is interesting to note that isolated sectors were most often found close to areas which were enriched with cerium (as shown by the numerous Ce-rich particles found at these locations) such as the lower part of the samples, close to where cerium was added prior to melting. This could indicate that the development of complete spheres by lateral extension of graphite sectors may have been hindered by the presence of Ce atoms.

It appears thus that Ce plays a complex role in cast iron melts: it contributes to deoxidizing the melt and would promote nucleation of new growth blocks while limiting their lateral extension. It is therefore likely that at some moment, lateral growth of sectors (isolated or part of an exploded precipitate) would have been blocked and their growth would have proceeded mainly radially, growing outwards along the $c$ axis.

\section{Discussion}

The model of 2D nucleation and growth recently described by Amini and Abbaschian [15] seems thus to govern growth of lamellar graphite in cast irons. Nevertheless, it was described as a layer by layer growth, in which each new layer corresponds to a graphene sheet, i.e., a monoatomic array of carbon atoms. Given the observations of growth blocks reported in this study it is thought that

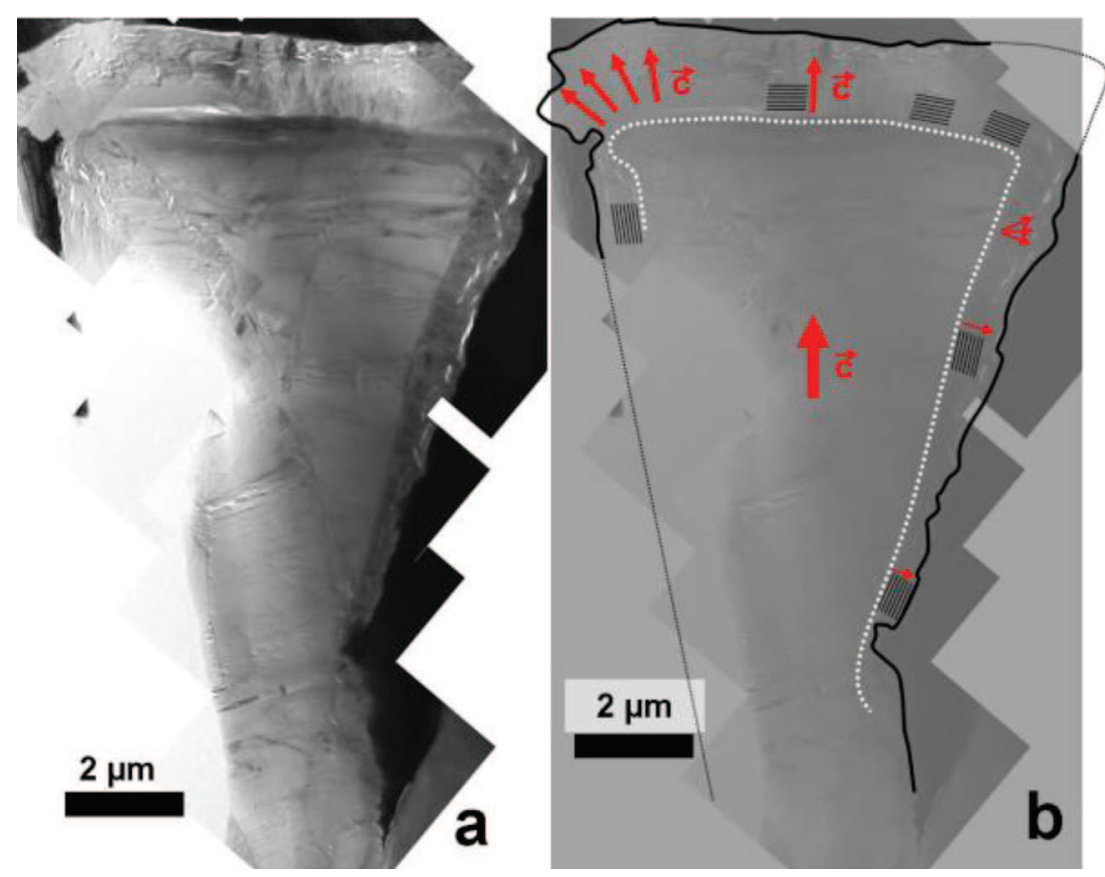

Fig. 13. a) Photomontage of bright field TEM images of a sector of primary exploded graphite b) schematic of graphene stacks with the $c$ axis orientation indicated by arrows. (A color version of this figure can be viewed online.) 
there should be a critical block height or thickness (for given conditions) required for further growth of graphite precipitates instead of atomic layers.

This is in line with results from previous studies, in which the assembly of structural units or graphite platelets has been reported to produce a great variety of macroscopic morphologies all presenting the same substructures but following different stacking sequences [44].

In an earlier study, natural graphite crystals were investigated and showed morphological similarities with those produced in this study [45]. According to these authors, the peculiar shape of the investigated crystals (which was nearly spheroidal) was the result of prominent layered growth, or platelet growth. According to these authors the platelets are likely to be rotated with respect to each other due to defects producing macrosteps and promoting the development of unusual graphite forms by growth of blocks. Bending of graphene sheets, and enhanced $c$ axis growth would be promoted by increasing carbon supersaturation associated with high cooling rates. It is important to point out that these authors reported inclination of the graphite blocks by $9-10^{\circ}$ and $13^{\circ}$ to the [0001] direction, as was observed in graphite spheroids in this study, and concluded that these misorientations resulted in nearly spherical aggregates. It appears that, opposite to what was stated in the past, screw dislocations are not required to form graphite spheroids and that their contribution to spiral growth around the $c$ axis of graphite is limited [46].

\section{Conclusions}

Different types of graphite precipitates found in graphitic cast irons have been investigated. Using mainly transmission electron microscopy, the inner structure of these precipitates was studied and showed that despite morphological differences at the microscopic scale flake and spheroidal graphite precipitates consist of growth blocks stacked upon each other. Crystals grow mainly by a 2D nucleation and growth mechanism, and the final shape of the precipitates is associated with the occurrence of crystallographic defects in the graphite lattice, namely misorientations and rotations during growth. The effect of several elements on graphite morphology was assessed through experiments of primary graphite growth in Fe-rich melts. It is shown that Ce, a known spheroidizing element, does not only play the role of an oxygen scavenger, but might also have a more direct effect on graphite growth, i.e. by limiting lateral growth of graphite. The phenomena described in these Ce-bearing cast irons have also been observed in alloys containing other impurities such as $\mathrm{Ca}, \mathrm{La}, \mathrm{Bi}, \mathrm{B}$ and $\mathrm{Mg}$ [30,47-49]. These elements, by adsorbing on graphite surfaces and promoting structural defects could lead to a myriad of graphite morphologies, made possible by the high flexibility of the graphite structure under different conditions. The results reported in this study show striking similarities with features of other carbonaceous materials obtained naturally or synthetically in a variety of conditions. Recent advances on graphene research have provided key information to further understand the phenomena occurring during graphite growth and resulting in the inner features of the precipitates observed in this study. All this information seems to point to a general 2-D nucleation and growth mechanism which can be affected by events occurring at the atomic scale level.

\section{Acknowledgements}

The authors would like to thank Muriel Veron for the orientation maps obtained by ACOM, Julien Zollinger for the preparation of the $\mathrm{Fe}-\mathrm{Sb}$ alloy and Azterlan for providing some of the materials used in this study.

\section{References}

[1] D.M. Stefanescu, Solidification and modeling of cast iron-A short history of the defining moments, Mater. Sci. Eng. A 413-414 (2005) 322-333.

[2] ASM Handbook, Properties and Selection: Irons, Steels and High Performance Alloys, vol. 1, ASM International, 1990.

[3] H. Morrogh, W.J. Williams, Graphite formation in cast irons and in nickelcarbon and cobalt-carbon alloys, J. Iron Steel Inst. 155 (1947) 321-371.

[4] V.S.R. Murthy, S. Seshan, Characteristics of compacted graphite iron, AFS Trans. 62 (1954) 373-380.

[5] M. Bazdar, H.R. Abbasi, A.H. Yaghtin, J. Rassizadehghani, Effect of sulfur on graphite aspect ratio and tensile properties in compacted graphite irons, J. Mater. Process. Technol. 209 (2009) 1701-1705.

[6] J. Bisault, G. Ryschenkow, G. Faivre, Spherulitic branching in the crystallization of liquid selenium, J. Cryst. Growth 110 (1991) 889-909.

[7] G. Faivre, On the mechanisms of spherulitic growth in polymer and iron melts, Adv. Mater. Res. 4-5 (1997) 17-30.

[8] M. Hillert, Y. Lindblom, The growth of nodular graphite, J. Iron Steel Inst. 148 (1954) 388-391.

[9] D.D. Double, A. Hellawell, Cone-helix growth forms of graphite, Acta Metall. 22 (1974) 481-487.

[10] B. Miao, D.O. Northwood, W. Bian, K. Fang, M.H. Fan, Structure and growth of platelets in graphite spherulites in cast irons, J. Mater. Sci. 29 (1994) 255-261.

[11] D.D. Double, A. Hellawell, The nucleation and growth of graphite-the modification of cast iron, Acta Metallurgica Materialia 43 (6) (1995) 2435-2442.

[12] C.R. Loper, K. Fang, Structure of spheroidal graphite in cast iron, AFS Trans. 116 (2008) 673-682.

[13] J.P. Sadocha, J.E. Gruzleski, The mechanism of graphite spheroid formation in pure Fe-C-Si alloys, Phys. Metallurgy Cast Iron 9 (1974) 442-459.

[14] K. Theuwissen, M.C. Lafont, L. Laffont, B. Viguier, J. Lacaze, Microstructural characterization of graphite spheroids in ductile iron, Trans. Indian Inst. Metals 65 (6) (2012) 627-631.

[15] S. Amini, R. Abbaschian, Nucleation and growth kinetics of graphene layers from a molten phase, Carbon 51 (2013) 110-123.

[16] I. Asenjo, J. Lacaze, P. Larrañaga, S. Mendez, J. Sertucha, R. Suarez, Microstructure investigation of small-section nodular iron castings with chunky graphite, Key Eng. Mater. 457 (2011) 52-57.

[17] J. Lacaze, N. Valle, K. Theuwissen, J. Sertucha, B. El Adib, L. Laffont, Distribution and effect of various doping elements during primary graphite growth in cast iron, Adv. Mater. Sci. Eng. 2013 (2013). Article ID 638451.

[18] K. Theuwissen, J. Lacaze, M. Véron, L. Laffont, Nano-scale orientation mapping of graphite in cast irons, Mater. Charact. 95 (2014) 187-191.

[19] B. Miao, K. Fang, W. Bian, G. Liu, On the microstructure of graphite spherulites in cast irons by TEM and HREM, Acta Metallurgica Materialia 38 (11) (1990) 2167-2174.

[20] J.P. Monchoux, Influence d'un recuit de ferritisation sur la microstructure et les mécanismes de fissuration en sollicitation monotone et cyclique de la fonte à graphite sphéroïdal perlito-ferritique, PhD thesis, INSA-Lyon, 2000.

[21] J.P. Monchoux, C. Verdu, G. Thollet, R. Fougères, A. Reynaud, Morphological changes of graphite spheroids during heat treatment of ductile cast irons, Acta Mater. 49 (2001) 4355-4362.

[22] B.E. Mironov, H.M. Freeman, A.P. Brown, F.S. Hage, A.J. Scott, A.V.K. Westwood, et al., Electron irradiation of nuclear graphite studied by transmission electron microscopy and electron energy loss spectroscopy, Carbon 83 (2015) $106-117$.

[23] P. Dierickx, C. Verdu, A. Reynaud, R. Fougères, A study of physico-chemical mechanisms responsible for damage of heat-treated and as-cast ferritic spheroidal graphite cast irons, Scr. Mater. 34 (2) (1996) 261-268.

[24] K. He, D.V. Edmonds, M.J.W. Green, P.E. Reynolds, Graphitisation of medium carbon steels. Mater Sci Tech 2004, AIST process Metall. 1 (2004) 207-215.

[25] K. He, H.R. Daniels, A. Brown, R. Brydson, D.V. Edmonds, An electron microscopic study of spheroidal graphite nodules in a medium-carbon steel by annealing, Acta Mater. 55 (2007) 2919-2927.

[26] I. Minkoff, S. Myron, Rotation boundaries and crystal growth in the hexagonal system, Philos. Mag. 19 (1969) 379-387.

[27] D.D. Double, A. Hellawell, Defects in eutectic flake graphite, Acta Metall. 19 (1971) 1303-1306.

[28] J. Zhang, J. Zhao, J. Lu, Intrinsic strength and failure behaviors of graphene Grain boundaries, ACS Nano 6 (3) (2012) 2704-2711.

[29] J. Zhang, C. Wang, Polycrystalline graphene curved by grain boundary for high performance nanoresonators, Comput. Mater. Sci. 87 (2014) 26-33.

[30] I. Minkoff, Hole formation in crystal growth by surface adsorption of an impurity, Philos. Mag. 12 (1965) 1083-1086.

[31] H. Okuno, A. Palnichenko, J.-F. Despres, J.-P. Issi, J.-C. Charlier, Synthesis of graphite polyhedral crystals using a combustion flame method, Carbon 43 (2005) 692-697.

[32] A.N. Jones, G.N. Hall, M. Joyce, A. Hodgkins, K. Wen, T.J. Marrow, et al., Microstructural characterisation of nuclear grade graphite, J. Nucl. Mater. 381 (2008) 152-157.

[33] C. Karthik, J. Kane, D.P. Butt, W.E. Windes, R. Ubic, In situ transmission electron microscopy of electron-beam induced damage process in nuclear grade graphite, J. Nucl. Mater. 412 (2011) 321-326.

[34] Y. Sun, L.B. Alemany, W.E. Billups, J. Lu, B.I. Yakobson, Structural dislocations in anthracite, J. Phys. Chem. Lett. 2 (2011) 2521-2524. 
[35] W. Patterson, H. Geilenberg, B. Lange, Anwachsversuche an graphitImpfkristallen aus kohlenstoffgesättigten Eisenschmelzen, Giesserei-Forschung 3 (1974) 121-128.

[36] S.E. Wetterfal, H. Fredriksson, M. Hillert, Solidification process of nodular cast iron, J. Iron Steel Inst. 210 (1972) 323-333.

[37] I. Minkoff, The Physical Metallurgy of Cast Iron, John Wiley and Sons, 1983.

38] S.E. Franklin, R.A. Stark, Application of secondary ion mass spectrometry to study of graphite morphology in cast iron, Metal Sci. 18 (1984) 187-200.

[39] S.E. Franklin, R.A. Stark, Further use of secondary ion mass spectrometry in the study of graphite morphology control in cast irons, MRS Symp. Proc. 34 (1985) 25-35.

[40] E.N. Pan, C.Y. Chen, Effects of Bi and Sb on graphite structure of heavy-section ductile cast iron, AFS Trans. 104 (1996) 845-858.

[41] I. Bleskov, K. Theuwissen, D. Connétable, J. Lacaze, Effect of antimony on primary graphite growth in cast iron - From ab-initio calculations to experimental observations, in: Annual Meeting Supplementary Proceedings, TMS, 2013, pp. 515-521.

[42] J.C. Ruth, M. Turpin, Structures de solidification unidirectionnelle des eutectiques fer-carbone, Mémoires Sci. la Rev. métallurgie 66 (1969) 633-640.

[43] K. Theuwissen, T. Duguet, J. Esvan, J. Lacaze, Distribution of some active elements in primary graphite precipitates, in: Conference SPCI-10, to Appear in International Journal of Cast Metals Research, 2014.

[44] S.H. Yoon, S. Lim, S.H. Hong, W. Qiao, D.D. Whitehurst, I. Mochida, et al., A conceptual model for the structure of catalytically grown carbon nano-fibers, Carbon 43 (2005) 1828-1838.

[45] V.N. Kvasnitsa, V.G. Yatsenko, J.A. Jaszczak, Disclinations in unusual graphite crystals from anorthosites of Ukraine, Can. Mineralogist 37 (1999) 951-960.

[46] C. Roscoe, D. Nagle, S.B. Austerman, Growth of graphite single crystals from iron-carbon solutions, J. Mater. Sci. 6 (1971) 998-1006.

[47] A. Munitz, I. Minkoff, Determination of the structure of graphite cast iron from melt analysis, in: 45th International Foundry Congress, 1948 (Budapest).

[48] A. Munitz, S. Nadiv, Effect of doping elements on the morphology of graphite grown from Ni-C melts, J. Mater. Sci. 17 (1982) 3409-3422.

[49] I. Minkoff, B. Lux, Ribbed growth of graphite in Ni-C solutions containing boron, Nature 225 (1970) 540-542. 